\title{
Strategic Leveraging: The Top-line Impact of Dynamic Capabilities
}

\author{
Vlatka Skokic ${ }^{1} \&$ Marko $\mathrm{Coh}^{2}$ \\ ${ }^{1}$ Faculty of Business, Economics and Law, University of Surrey, UK \\ ${ }^{2}$ Maxxim Consulting, London, UK \\ Correspondence: Vlatka Skokic, University of Surrey, Faculty of Business, Economics and Law, GU2 7XH, \\ Guildford, UK. Tel: 44-1483-689758.
}

Received: July 17, 2015

Accepted: July 30, 2015

Online Published: August 21, 2015

doi:10.5430/ijba.v6n5p1

URL: http://dx.doi.org/10.5430/ijba.v6n5p1

\begin{abstract}
It is commonly assumed that the world's most successful companies have built their success on the basis of their own internal competencies and relentless single-handed pursuit of market impact. However, as Iansiti and Levien (2004) show, using examples of Microsoft, Wal-Mart, Dell and others, many of those firms have attained market leadership in their respective industries by developing and nurturing business ecosystems of partner firms. By embedding their competencies in technologically sophisticated and standard-setting platforms have those large firms attracted smaller firms to become partners and enabled them to leverage platforms, build on top of them and pursue particular niche. In doing so, large firms have become keystone players for their industry and expanded their impact, as in addition to their own activity they created basis for activity of bulk of smaller firms (niche players). This leads to the following question: how does such leveraging impact top-line and bottom-line growth of both keystone players and niche players? This paper addresses top-line impact in the context of niche players in the IT industry. Building on dynamic capabilities framework by Teece et al. (1997) and literature on measurement of intangible assets, this paper: i) presents conceptual model that shows how niche players can increase their competitiveness by strategically leveraging competencies of keystone players, and ii) proposes measures to estimate impact of such leverage on top-line growth of niche players.
\end{abstract}

Keywords: dynamic capabilities, partnerships, alliances, small firms, leveraging, performance, measures

\section{Introduction}

In recent years a new paradigm of strategic management, dynamic capabilities approach, has emerged. It focuses on developing understanding of what generates competitive advantage of firms in dynamic, rapidly changing markets. The approach has gained significant following; however it has also been criticized as being tautological and inoperable. At the same time, popular business literature started to cite examples of firms that have attained market leadership by drawing on resources and capabilities of firms in their environment. It seemed that dynamic capabilities concept lends itself as an appropriate tool to analyse properties of strategic management in networked environments, as it explicitly discusses integration of external competencies, i.e. competencies developed by firms in focal firms' environment, that can not be readily bought and sold in factor markets. This paper endeavours to further understanding of how does integration of external competencies take place, how could small firms (as opposed to most of the literature that discusses large firms) leverage competencies of large firms in their environment to their benefit, and what are the performance implications of such integration efforts. The paper investigates the concept in the context of Microsoft's business ecosystem. In the final part of the paper, framework for estimation of performance contribution of integration of external competencies is presented, and some venues for further research are outlined.

\subsection{Dynamic Capabilities - The Concept}

The concept of dynamic capabilities is an emerging paradigm in the field of strategic management. Authors that have been developing the concept have endeavored to identify sources of competitive advantage of firms in dynamic markets and have presented mechanisms that underlie effective deployment and development of dynamic capabilities. Intellectual antecedents to dynamic capabilities approach include evolutionary economics (Nelson \& Winter, 1982) resource based view of the firm (Wernerfelt, 1984) and organizational learning (Argyris \& Schon, 1978). The former two research streams build on pioneering work by Schumpeter (1942). Since mid 1990s, a number of authors have 
contributed theoretical and empirical pieces of research that have highlighted various aspects of dynamic capabilities Eisenhardt \& Martin, 2000; Pavlou \& El Sawy, 2011; Teece \& Pisano, 1994; Wang \& Ahmed, 2007; Winter, 2003; Zollo \& Winter, 2002). Given that general consensus on nature and properties of dynamic capabilities has not yet emerged, the paper will provide overview of the concept by contrasting and integrating key points of most notable contributions addressing the definition of dynamic capabilities and sources of competitive advantage

Teece, Pisano and Shuen (1997) have observed that winners in the global market place have demonstrated timely responsiveness and rapid and flexible product innovation, along with managerial ability to effectively coordinate and redeploy internal and external competencies. They term this ability to achieve new forms of competitive advantage 'dynamic capabilities', to emphasize two aspects of strategy that previously weren't the main focus:

- Dynamic: to emphasize capacity to renew competencies to achieve alignment with the changing business environment

- Capabilities: to emphasize key role of strategic management in adapting, integrating and reconfiguring internal and external organizational skills, resources and competencies, to match the requirements of the environment

They define dynamic capabilities as the 'firm's ability to integrate, build and reconfigure internal and external competences to address rapidly changing environments' (p. 516). In order to comprehend that definition clarification of organizational competencies and core competencies is needed. Teece et al. (1997) define organizational competencies as 'firm specific assets that are assembled in integrated clusters to enable distinctive activities to be performed' (p. 516) and core competencies as competencies that 'define firm's fundamental business' (p. 516). Examples of competence are miniaturization and systems integration, whereas imaging in the case of Kodak and integrated data processing in the case of IBM could be considered core competencies of the respective firms.

Eisenhardt and Martin (2000) define dynamic capabilities as 'the firm's processes that use resources - specifically the processes to integrate, reconfigure, gain and release resources - to match and even create market change' ( $\mathrm{p}$. 1107). Dynamic capabilities thus are 'organizational and strategic routines by which firms achieve new resource configurations as markets emerge, collide, split, evolve and die' (p. 1107). According to Eisenhardt and Martin (2000) managers deploy dynamic capabilities to alter resource base to generate new value-creating strategies.

Winter (2003, p. 983) builds definition of (dynamic) capabilities on the broader concept of organizational routine: 'an organizational capability is a high level routine (or collection of routines) that, together with its implementing input flows, confers upon an organization's management a set of decision options for producing significant outputs of a particular type'. In other words, capability is a routine that enables managers to choose among different ways of producing output. Routine is a 'behavior that is learned, highly patterned, repetitious, founded in part in tacit knowledge' ( $p$ 983). Winter distinguishes between ordinary ('zero-level') capabilities and dynamic capabilities. While the former permit a firm to 'make a living' the latter operate to 'extend, modify or create ordinary capabilities'. Winter also addresses criticisms that dynamic capabilities don't exist by presenting hypothetical example of a firm in equilibrium that exercises stationary process of selling the same product on the same scale to the same population of customers over time. Capabilities that support such process are zero-level. However, capabilities that would effectuate change of that process wouldn't be zero level. Capabilities that support geographical expansion of firms such as McDonald's are a prototypical example of higher-level capabilities, i.e. dynamic capabilities. Apart from being higher-level, these capabilities are also highly patterned and routine. Their existence is according to Winter (2003) concluding evidence that dynamic capabilities exist.

\subsection{Sources of Competitive Advantage}

Although Teece et al. (1997) and Eisenhardt and Martin (2000) provide similar definitions of dynamic capabilities, they ascribe different roles to dynamic capabilities with respect to competitive advantage. While Teece et al. (1997) contend that competitive advantage of firms in dynamic markets rests on distinctive organizational processes, shaped by firm's specific asset position, in turn shaped by fir's evolution path, Eisenhardt and Martin (2000) state that resource recombinations, rather them dynamic capabilities themselves, are the source of competitive advantage. This important distinction stems from differences in their respective treatment of organizational processes.

In Teece et al.'s (1997) view the central strategic problem is which difficult-to-imitate internal and external competencies are most likely to support valuable products and services. This problem can be rephrased as a problem of what to invest in. Since possible investment choices at any point in time are influenced by past decisions, each time a firm makes an investment it actually makes a long-term, almost irreversible commitment to particular domain of competence. Past decisions shape firm's position, which is a specific endowment of skills, technology assets, complementary assets, customer base etc. that a firm possesses in a given point in time. In contrast with 
microeconomics, which posits that firms have infinite range of technologies to choose from and markets to occupy, evolutionary economics (Nelson \& Winter, 1982) recognizes that at any point in time firms are limited in their investment alternatives. This is so because learning tends to be local, i.e. opportunities to learn are close to previous activities. Therefore, firm's history constrains its future behavior, implying that investments are often more long term than is commonly thought.

On the other hand, Eisenhardt and Martin (2000) see dynamic capabilities as consisting of specific routines that form identifiable and well-researched processes such as product development, strategic decision making and alliancing. In their view dynamic capabilities are organizational processes employed to alter resource configurations of firm. In contrast with Teece et al.'s (1997) view that organizational processes themselves act as a source of competitive advantage, Eisenhardt and Martin (2000) ascribe this role to resource reconfigurations, therefore organizational processes function as means to generate competitive advantage.

Another important distinction between Eisenhardt and Martin's (2000) and Teece et al.'s (1997) view is that the former see organizational processes as exhibiting significant commonalities across firms, whereas the latter argue that organizational processes are idiosyncratic to individual firms. Teece et al. (1997) see organizational processes as distinctive among firms. They apply resource-based view lens that sees resources as idiosyncratic and consequentially a source of competitive advantage, to organizational processes. On the other hand, Eisenhardt and Martin's (2000) view implies that there is such thing as 'best practice'. That implication strengthens their view that organizational processes themselves can not be a source of competitive advantage, as a number of firms can develop organizational processes that, although different in details, produce the same outcomes. For instance, common feature across knowledge creation processes is explicit linkage between the focal firm and knowledge sources outside the firm (particularly in high-tech firms). While these linkages are necessary for effective knowledge creation, they can take varied forms including formal alliances and informal personal relationships.

Eisenhardt and Martin (2000) go further to strengthen their assertion by providing taxonomy of organizational processes that constitute dynamic capabilities. They group these processes in four categories, which include processes that:

- Integrate resources

- Reconfigure resources

- Gain resources

- Release resources

Dynamic capabilities that integrate resources include product development routines and strategic decision making. Toyota has used its superior product development skills to achieve competitive advantage in the automotive industry. In the strategic decision making, managers integrate their business, functional and personal expertise to make choices that shape strategic direction of firms. Eisenhardt and Martin (2000) quote examples of dynamic capabilities that reconfigure resources. They include transfer processes (used by managers to replicate, transfer and recombine resources in the firm), coevolving (connecting webs of collaborations among various parts of the firm) and patching (strategic processes that re-align match up of businesses to changing market conditions and opportunities). Dell is well known for patching, as it constantly segments businesses to match shifting customer demand. Dynamic capabilities that gain resources include knowledge creation processes (crucial in industries such as pharmaceuticals, where cutting edge knowledge is essential for performance) and alliance and acquisition routines that bring new resources into the firm from external sources (Hewlett Packard has very strong alliancing process that positively affects its performance, while biotechnology firms with strong alliancing processes also exhibit superior performance). Finally, dynamic capabilities that enable firms to shed resources that are no longer needed to support competitive position are crucial when markets undergo change.

For the sake of clarity, it is worth noting what Teece et al. (1997) and Eisenhardt and Martin (2000) consider by resources. Eisenhardt and Martin (2000), in their succinct definition, define resources as specific physical (e.g. specialized equipment), human (e.g. expertise in IT) and organizational (e.g. superior sales force) assets that can be used to implement value creating strategies. Resources include competencies that are fundamental to the competitive advantage of a firm, such as supply chain management for a retail firm or molecular biology for biotech firms. Common to both approaches is that they consider as resources only specialized assets, whereas those assets that can be bought and sold in the market are considered as the product factors.

This sections show that scholars have yet to come to the consensus on whether organizational processes by themselves or resource configurations that they create constitute sources of competitive advantage, however there 
seems to be an agreement that sets of particular organizational processes, termed dynamic capabilities, are essential for development of competitive advantage in dynamic markets.

\subsection{Dynamic Capabilities in the Networked Environments}

The important question that remains though is whether firms in dynamic markets should develop their competitive advantage by relying solely on their internal resources or should they try to access resources from the environment. Winter (2003) pointed out that development of dynamic capabilities is often a costly endeavor and that firms may often resort to ad hoc problem solving. Ad hoc problem solving is usually sufficient for the firms to 'make a living', however it doesn't enable firms to develop and sustain competitive advantage in dynamic markets. Furthermore, firms often have limited internal managerial and technological capacity to develop their capabilities to the level needed for viable participation in dynamic markets. Solely internal development of knowledge needed to support dynamic capabilities may result in duplication of efforts, as firms may end up developing knowledge already present in their environment.

The rationale for firms to consider establishment of formal and informal linkages with organizations and individuals in their environment is that although any cooperation has several risks associated with it (appropriation of knowledge, opportunistic behavior, lock-in in unproductive arrangements etc.), it is reasonable to believe that benefits flowing from access to pool of external knowledge, competencies and resources can exceed costs of cooperation.

Powell, Koput and Smith-Doerr (1996) analyzed research oriented SMEs in biotech industry and found that the locus of learning in that industry is located in networks of firms, and that higher centrality was associated with higher performance. Their findings are important and have two implications: that the network a firm finds itself in does matter (as learning opportunities for a firm depend on knowledge and capabilities of network members), and that positioning in the network matters as well. Iansiti and Levien (2004b) developed these notions further. They analyzed productivity in the software, biotech and the internet industries from 1995 to 2002 . They found that cumulative returns on invested capital were positive for the software industry, while for biotech industry were slightly negative and for internet industry they were significantly negative. Furthermore, they observed constant gap in productivity of the software and biotech industries, whereas internet industry experienced sharp drop in return on invested capital after year 1996. Firm's performance can deteriorate if technological change renders capabilities of its coopetitors (suppliers, complementors, partners and customers) obsolete. Therefore it is important that a firm tries to identify and enter networks whose members developed capabilities to withstand technological and other environmental shifts.

It seems reasonable to believe that many networks consisting solely of SMEs are likely not to meet those criteria. Again we can invoke Winter's (2003) argument that firms, including SMEs, often have a tendency to resort to ad hoc problem solving, which in time results in inadequately developed dynamic capabilities. Additionally, by partnering with SMEs similar to them firms might fall under 'strong ties are weak ties' situation. The rationale is that actors that have strong ties among themselves are likely to possess similar levels of capabilities and resources (including network resources). Therefore they don't enhance each other's sources of competitive advantage and that makes strong ties weak in terms of value.

It has been argued that firms operate in networked environment. We need to gain more insight into how is such networked environment structured and how it functions. In their innovative and persuasive treatment of modern business environment, Iansiti and Levien (2004a; 2004b) suggest that business networks are analogous to biological ecosystems in that they both include loosely connected participants, who to a greater or lesser extent share a common fate. What is more striking though is that both business networks and ecosystems tend to be asymmetrically distributed, i.e. that some actors tend to have significantly more ties than other actors. These actors play the role of the hub, and activities of hubs have significant impact on health of the ecosystem or business network as a whole. They classify behavior of firms that occupy hubs in business networks (business ecosystems) as keystone, landlord and dominator behavior.

Firms that act as keystones improve health of the whole ecosystem by providing stable and predictable set of common assets that other firms use to develop their own offerings. Iansiti and Levien (2004a, 2004b) suggest that ecosystem's health can be assessed on three dimensions: productivity; robustness; and niche creation.

Keystone players increase productivity of the ecosystem by simplifying complex task of connecting network participants to one another by offering common platforms (typical examples are Microsoft's operating systems and tools). They also contribute to increased robustness of the ecosystem by consistently incorporating technological innovations in platforms and providing reliable points of reference for other participants. Finally, keystone players encourage niche creation by offering their innovative technologies to a variety of firms and organizations. Keystone 
players employ strategies of creating and sharing value with other ecosystem members not out of altruism but because it is good business. The reason is that platforms are only effective if they are widely used, due to the economic phenomena of network externalities and lock-in effect. Network externalities is the term to describe a property of a certain product, service or technology of becoming more valuable as more people start to use it. Lock-in effect occurs when scale of users and complementors of particular technology exceeds critical mass and switching costs significantly exceed switching benefits.

By applying what Iansiti and Levien (2004a, 2004b) term landlord strategy, hub firms try to extract as much value from an ecosystem as possible without trying to control it. These firms recognize that networks have high potential to create value, however they capture too much of it for themselves. Landlord strategy is always dangerous and ecosystems characterized by the presence of landlords are likely to experience deteriorating health. Dominator firms employ strategies that have elements of both keystone and landlord strategies. Goal of a dominator strategy is to control both creation and capture of the value in an ecosystem. These firms have tendencies to vertically integrate, i.e. try to take over their ecosystem. Like landlords dominators have the potential to do damage to their ecosystems, however the dynamics can be different. In terms of impact on productivity, landlords drain incentives to innovate from the ecosystem while failing to create any themselves. Dominators differ in that they take it up to themselves to deliver innovations. The productivity of an ecosystem is then determined by dominator's internal R\&D capacity. Landlords are not concerned with development of stable core that other ecosystem members can build on, whereas dominators are. However, in time lack of diversity in ecosystems characterized by the presence of dominators makes those ecosystems fragile and less resilient in the face of technological shifts. Landlords stifle niche creation to an even larger extent than dominators, since they extract so much value out of their ecosystem that they impoverish ecosystem members, who can not build meaningful new businesses and pursue new niches.

As Gulati (1999) and Dyer and Singh (1998) point out, membership in networks confers upon firms access to resources and competencies of other network members. Since earlier discussion suggests that networks most likely to offer the most opportunities for niche creation (natural strategic direction for SMEs) are those characterized by major firms employing keystone strategy, SMEs could improve their resource and competence endowment and potentially raise level of performance by joining such networks. Furthermore, since position in the network matters, SMEs would likely benefit from network position close to the keystone firms, which could be achieved by actively cultivating relationships with them.

However, cultivation of such relationships is unlikely to generate significant benefits for SMEs per se. Rather exploration should be complemented by exploitation. By exploitation we mean active integration of accessible competencies of keystone players, which tend to develop through internal activities of keystone firms and activities of other members of an ecosystem. Iansiti and Levien (2004b, p. 149) define platforms as 'set of solutions to common problems'. If we follow their definition we see that core competencies of keystone firms often involve the capacity to set standards by offering solutions that become building blocks of the offerings of ecosystem's members. Keystone firms make platforms available as widely as possible, as that increases their value. By accessing those platforms SMEs effectively integrate keystone firms' competencies as they are embodied in platform solutions. The exercise of platform integration has the potential to improve level of SMEs' competencies as it demands at least partial understanding of technologies embodied in the platforms. As platforms generally embody the latest technologies, platform integration exercise is in fact also competence developing exercise. However, improved competencies and integrated platforms can fully benefit SMEs only if SMEs develop distinctive offerings on the basis of the platforms. Limited resource endowments allow SMEs to focus on a relatively narrow niche, and key to success in niche markets is differentiation. Process of integration of internal competencies of SMEs, instrumental in their development of offerings, with external competencies that define shape of building blocks in ecosystems, ultimately rests upon dynamic capabilities of SMEs.

Preceding discussion suggests that it may be valuable for firms to try to enter networks, whose members include major firms, who tend to possess superior resources and capabilities. Three common objections to such intention might be that first, major firms are not interested in building business ties with SMEs who can not bring any significant contribution to the table, second, that major firms would dominate such networks at the expense of SMEs' performance, and third, that superior resources and capabilities of major firms would not be of much use to SMEs. The paper argues that these scenarios are not necessary in all situations and that there is potential to improve SMEs' performance by participating in business networks characterized by presence of major firms.

\subsection{Relationship Capability}

Keystone players, landlords and dominators have been characterized as hubs that employ different strategy and have 
disproportionately large number of ties with other participants in the ecosystems. This approach is followed in defining niche players, who are small, focused businesses, that exhibit 'typical' or less than typical number of ties/relationships with other ecosystem participants. Typical number of ties is the modal value of ties for participants in a particular ecosystem. Such characterization of niche players is actually characterization that applies to most SMEs, therefore the paper will refer to SMEs as niche players, to build a coherent model of strategy for SMEs in dynamic markets based on Iansiti and Levien's (2004a) taxonomy of participants in business ecosystems.

Key to success for a niche player is specialization in particular domain of competence. By leveraging relationships with other ecosystem participants, who possess complementary assets, niche players can achieve specialization while at the same time assembling complex system-level solutions often demanded by customers. Firm NVIDIA is a textbook example of a successful niche player. Its core competence is development, design and marketing of graphics processors and related software for PCs, workstations and digital entertainment platforms. By focusing on its core competence and leveraging physical assets (Taiwan Semiconductor Manufacturing Company's manufacturing facilities), as well as intellectual assets (such as third-party design tools), NVIDIA became a highly successful niche player in the business ecosystem of semiconductors and integrated circuits. The example of NVIDIA suggests that the elements of successful niche strategy are identification of keystones and other niche players in the environment, establishment of access to their assets (competencies), integration of competencies and development of specialized offerings on the basis of these competencies. Since strategic process then revolves around leveraging the relationships, I term combination of dynamic capabilities, needed to support such process, relationship capability.

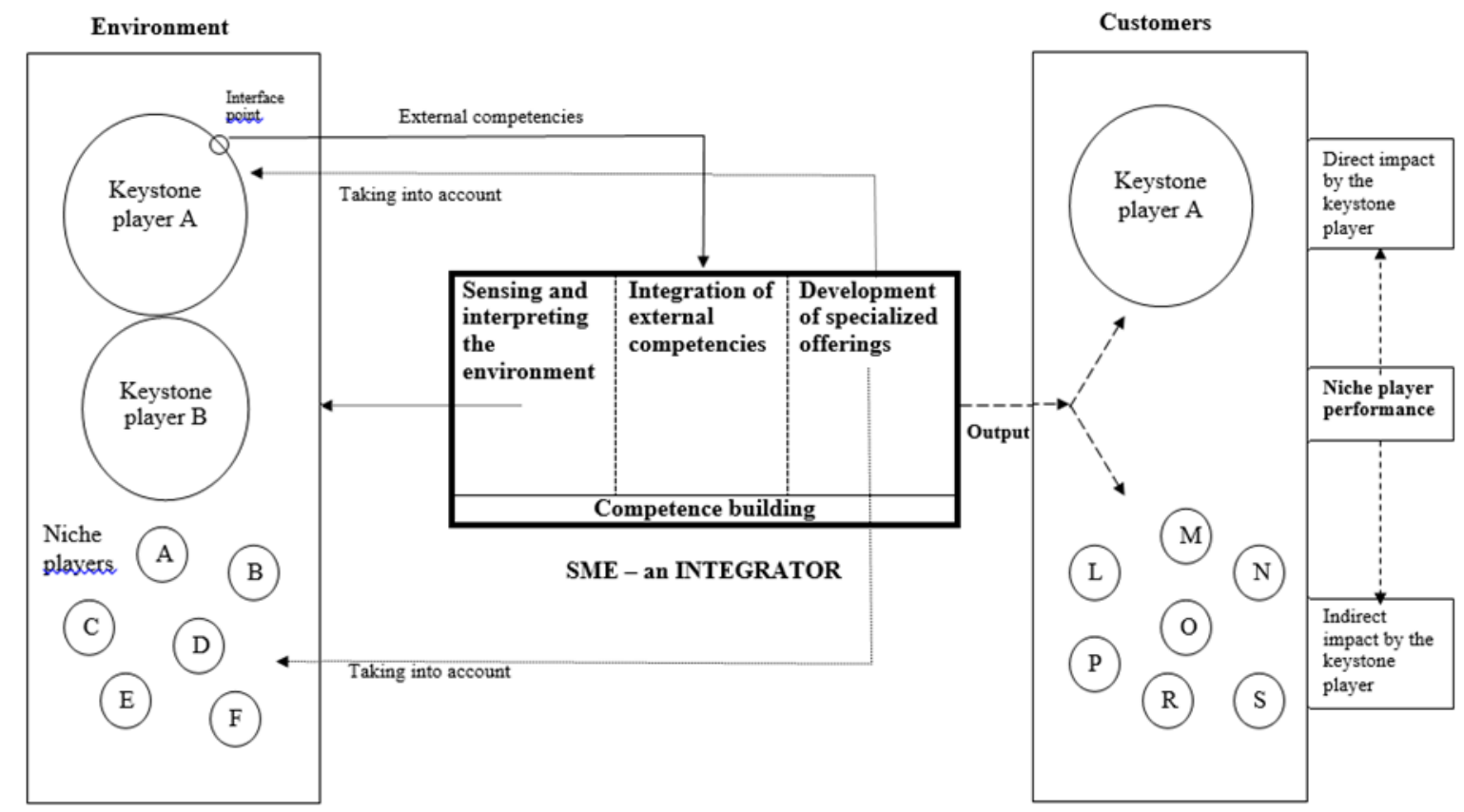

Figure 1. Relationship capability

Figure 1 presents the concept of relationship capability. The figure consists of three parts: the firm (SME), its environment (consisting of keystone players and niche players) and its customers. The firm is presented as an integrator, performing three interrelated groups of processes: sensing and interpreting the environment, integration of external competencies and development of specialized offerings. Activities firm performs to improve these three groups of processes are denoted as competence building. Following studies of Helfat and Raubitschek (2000) and Eisenhardt (1989b), we term the firm integrator since the activities mentioned above could be considered to constitute integrating dynamic capability. Since integrating knowledge underlying dynamic capabilities can be a source of competitive advantage, we aim to examine what integrating practices focal firms perform and whether these practices might confer competitive advantage on these firms. 
Processes employed to sense and interpret the environment are aimed at identification of keystone players and niche players in the firm's environment and identification of relevant strategic elements associated with these two groups of players. Such strategic elements include: types of products and services offered by keystone players and niche players, markets these types of players are in and will enter in the near future and characteristics of the strategic behavior of both type of players (e.g. technology leader/ technology follower, speed of reaction to changes in environment etc.).

Integration of external competencies is a process aimed at enhancement of competence base of a firm. Integration capability is often critical in technology intensive industries, as keystone players' core competencies include setting standards of the industry. In that kind of situations, niche players need to develop capability to efficiently and timely integrate core competencies of keystone players, embedded in platforms or core products. Third group of processes that an integrator performs constitutes development of specialized offerings. Generally development of offerings follows integration of new generations of platforms or core products, as niche players build their offerings on top of keystone players' outputs. Typical example is Microsoft's .NET platform, which numerous niche players around the world use as a basis for their offerings. Another example is customer demand information Dell and Wal-Mart provide to their supply chain partners. Such information is actually a platform, basic building block of business strategy of niche players that supply Dell and Wal-Mart. Niche players gain access to platforms or core products through interface points that keystone players establish to stimulate adoption of their platforms. Examples of such interface points are partner programs or web portals that enable easy and efficient access.

Niche players have to develop specialized offerings, as they lack economies of scale or scope that large players enjoy. Consequently niche players can not compete on costs. Capability to develop distinctive offerings therefore has to be at the center of product/service development activities to enable niche players to stay in the market and generate positive business results. To develop distinct offerings niche players need to take into account activities of both keystone players and other niche players.

Relationship with a keystone player can have varying impact on market position and business results of niche players. In Figure 1 we distinguish between niche players that are suppliers to a keystone player (and potentially other customers) and niche players that sell their offerings only to customers other than keystone player. Based on this distinction, we distinguish between direct and indirect impact of keystone player on business results of niche players. Those niche players that supply a keystone player and other customers experience direct impact of keystone player, as they depend on both strategic and revenue side on the keystone player (the former due to the reliance on competencies of the keystone player). Those niche players that supply only customers other than keystone player experience indirect impact, as their revenues are not generated from business with the keystone player, while competencies of keystone player remain strategically important for such niche players.

\section{Method}

Review of relevant literature on strategic management revealed that there has been little treatment of ways in which firms could make use of external competencies, i.e. competencies that other firms in their environment possess, in the pursuit of competitive advantage. As SMEs as subject of investigation have been until recently in domain of research streams other than strategic management (e.g. entrepreneurship), strategic management has been rather silent on how might managerial practices and processes in SMEs support integration of external competencies and development of specialized offerings. As a result, dynamic capabilities in SMEs have been rather unexplored (Della Corte \& Del Gaudio, 2012). Literature suggests that when dealing with relatively under-explored phenomena, inductive theory building research approach is appropriate. Glaser and Strauss (1967) suggested grounded theory building using comparative method. This method relies on continuous comparison of collected data and theory, and results in theoretical categories based solely on evidence. Eisenhardt (1989b) suggested more systematic approach and developed roadmap for building theories from case study research. The paper combines these two approaches, as the theoretical constructs were continually sharpened with newly acquired field data.

\subsection{Sampling}

Theoretical sampling is used as a main sampling startregy (cases were chosen for theoretical, not statistical reasons, Glaser and Strauss, 1967) as it allows choice of cases in which the processes of interest are observable. The paper studies seven small and medium-sized information technology (IT) companies operating in Central and Eastern Europe. Unifying characteristic of these companies is that they are all partners of Microsoft. Choice to study Microsoft partner companies was based on presumption that phenomena of interest might be readily observable, as the business model of Microsoft is built on partnership with niche players that develop their offerings on the basis of Microsoft's platforms. 
As the general aim of this study is to uncover what constitutes competitive advantage of SMEs in dynamic markets, we approached the selection of niche players to be included in the sample by asking representatives of Microsoft in the country subsidiary to recommend niche players that are 'the best in class', i.e. have competitive advantage relative to other niche players in their business sub-domain (e.g. small systems integrator, large systems integrator etc.). To be included in the sample, firms also had to exhibit revenue growth and profitability in the past three years. All recommended niche players but one passed these criteria. We discussed the issue with Microsoft representatives and they argued that that particular niche player has indeed experienced a drop in profitability and revenues, however they believed that the firm has successfully redefined its business and regained its competitive advantage in the current year. Therefore due to the experts' opinion that niche player was included in the sample.

\subsection{Data Collection}

The data were collected through extensive field work. The rationale was that in order to understand complex phenomena embedded in intra- and inter-organizational processes, researcher needs to obtain rich, mainly qualitative data on these processes. The field work was carried out in two phases. In the first phase, we conducted in-depth interviews with twelve executive managers from seven niche players. In five companies, we conducted separate interviews with two individuals and in two companies we conducted interview with one person per company. In the second phase, we asked respondents to validate and complement summarized and interpreted findings based on the interviews. That kind of research approach ensured robustness of the findings, as well as enhanced practical implications. We gained additional feedback by organizing a joint meeting with the representatives of Microsoft in the region and interviewees.

\section{Results}

\subsection{Relationship Capability in Practice: Niche Players/Microsoft's Partners}

Figure 2 presents findings in the context of relationship capability framework introduced in Figure 1.

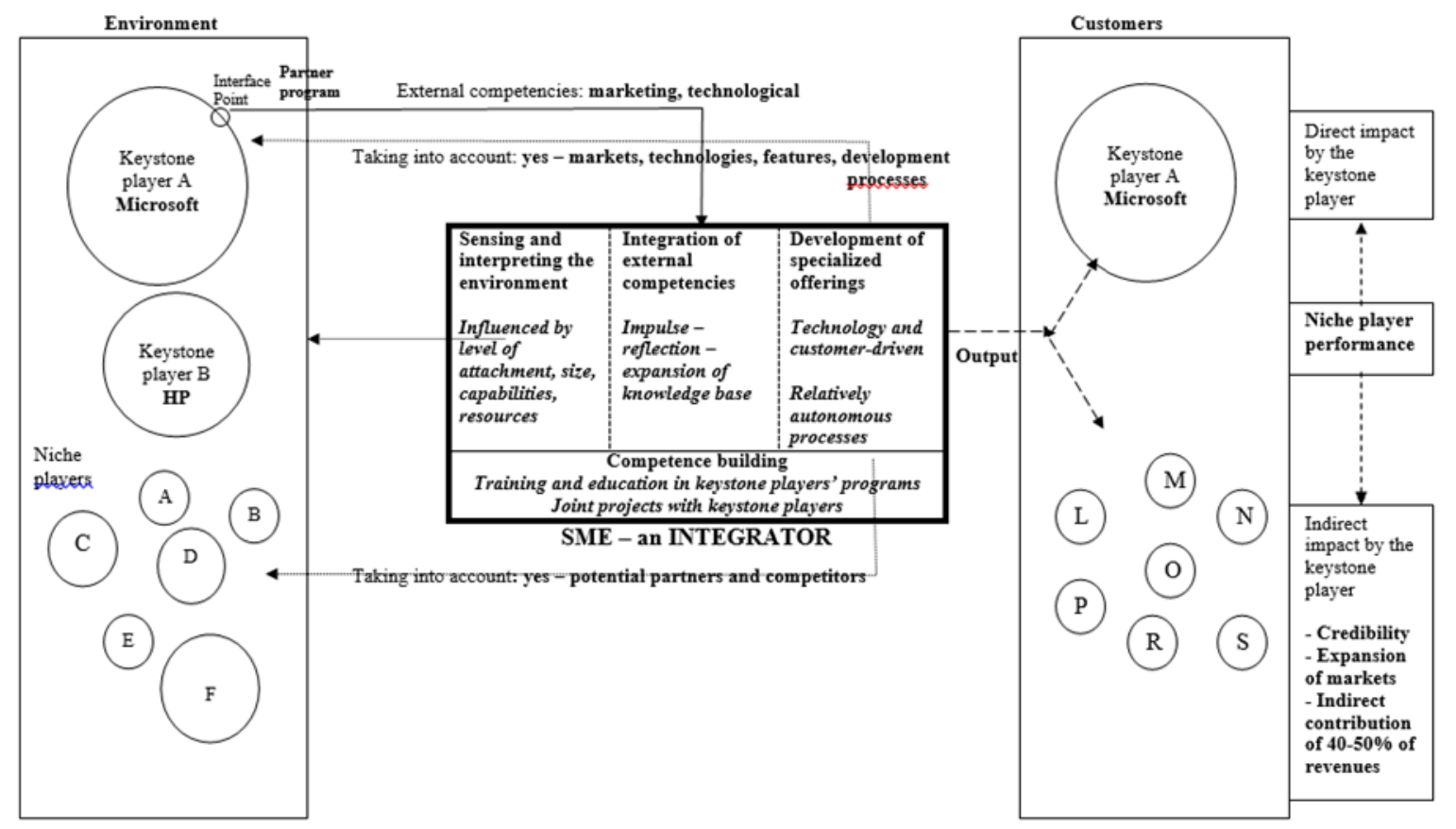

Figure 2. Relationship capability/Niche players-Microsoft's partners

External environment of niche players in the sample is characterized by presence of one keystone player (Microsoft) and another major firm (HP) that functions as the most important keystone player to two niche players in the sample. Other niche players function as potential partners and competitors. Sensing and interpreting of the environment is influenced by level of attachment to Microsoft, size, capabilities and resources. Niche players in the sample integrate 
marketing and technological competencies from Microsoft. Integration takes place in a three-phased process, consisting of impulse phase, reflection phase and expansion of knowledge base phase. Integration of Microsoft's competencies is central competence building activity, and it occurs through training and education in Microsoft's programs and through joint projects. Niche players adopt technology-driven and customer-driven strategic orientation, which influences their market positioning and capabilities that support differentiation. Although development of offerings takes place in a relatively autonomous fashion, niche players take into account activities of both keystone players and other niche players. All companies in the sample are selling their offerings to customers other than Microsoft therefore they experience indirect impact of cooperation. Most positive gains from cooperation is credibility and expansion of markets, whereas cooperation with Microsoft contributes on average $40-50 \%$ of niche players' revenues in the form of sales of licenses for Microsoft's products and sales of solutions developed on Microsoft's platforms.

\subsection{Results of Cooperation with Microsoft}

The interviewees quoted similar gains they thought arose from cooperation of their firms with Microsoft. The gain stated the most was credibility; respondents unequivocally concluded that collaboration with Microsoft raised credibility in their firms in the eyes of customers. To capitalize on raised credibility, niche players make use of co-branding (using Microsoft's brand when promoting their offerings), which is especially relevant when entering international markets. Microsoft's participation in major international events such as Cebit and presentation of its partners there expands range of accessible markets for these partners. In local market, Microsoft's events and other promotional activities serve to increase market's awareness of niche players that Microsoft promotes. Third most cited group of gains was technological gains. Respondents cited ongoing technological support in real time and efficient access to the newest technologies as the most important technological gains.

The respondents were also asked to assess effects of cooperation on innovativeness, sales growth and revenues. According to the respondents, cooperation with Microsoft has an insignificant effect on innovativeness. They cited one situation when keystone players positively influence innovativeness of niche players, and that is when the platform expands. In most cases it results in integration of certain functionalities, previously provided only by niche players' offerings, in the platform. When that occurs, niche players need to innovate and provide offerings that have functionalities not provided by the expanded platform. If we consider innovativeness as a proxy for differentiation capability, we can conclude that dynamic capabilities that support development of differentiated offerings are not positively affected by cooperation with a keystone player. Two respondents argued that tight cooperation that turns into an intensive following of a keystone player may result in lower innovativeness, as firms in such situations tend to neglect their own differentiation capabilities.

On average cooperation with Microsoft contributes $40-50 \%$ of niche players' revenues. $50 \%$ of Microsoft-related revenues are generated with sales of licenses for Microsoft's products, and other $50 \%$ with services and solutions developed on the basis of Microsoft's platforms. In four cases out of six niche players allowed for a possibility that they wouldn't exist in such form as they do today if they haven't cooperated with Microsoft. However, they believe they would cooperate with some other keystone player if Microsoft didn't exist. On the issue of contribution of cooperation to sales growth respondents had divergent opinions. There were a few negative responses, especially related to Microsoft's provision of sales leads and establishment of contacts with desired clients, and a few positive comments, mainly from niche players less attached to Microsoft. We can conclude that cooperation with Microsoft raises profile of niche players, however sales growth can only be achieved by the niche players themselves.

\subsection{Top-line Impact of Relationship Capability}

Empirical investigation revealed that increased credibility is the primary benefit niche players in the sample derive from partnership with Microsoft. Credibility, in turn, is derived from customers' perception of Microsoft's brand. Impact of Microsoft's brand is a result of deliberate build-up of marketing competencies, and by partnering with Microsoft and via co-branding, niche players effectively integrate end-product (brand impact) of those marketing competencies. According to conceptualisation of relationship capability as consisting of sensing and interpreting the environment, integration of external competencies and of differentiation, we can estimate the value of second element which represents dynamic capability. Value of integration of external competencies can be determined by estimating proportion of revenue that can be directly attributed to market impact of Microsoft's brand. In order to do that, we first have to answer two questions: 1 . to what extent is customers' perception of partners' offerings driven by Microsoft's brand, to what extent by their respective brands, and 2. to what extent are factors that drive demand for offerings of niche players affected by impact of Microsoft's brand and to what extent by partners' brands. In the following paragraphs the three-step process for estimation of proportion of revenue driven by Microsoft's (or 
generally, by keystone player's) brand is outlined.

1. Identify demand drivers

- firms would identify demand drivers relevant for particular customer by surveying them, asking them to state at least five demand drivers and rate them according to their importance when making purchasing decisions by assigning them values on a scale of one to ten

- by summing values for all demand drivers, firms could calculate proportion that each demand driver contributes to total; those proportions would serve as a proxy for proportion of total revenues generated by each demand driver

2. Estimate association with Microsoft's and partner's brand

- firms would survey customers to what extent is brand perception of both Microsoft and niche player associated with particular demand driver; customers would rate association with Microsoft's and partner's brand on a scale of one to ten, with one being 'there is no association between respective brand and individual demand driver', and ten being 'demand driver is fully associated with the respective brand'

- by summing values for both brands on all demand drivers, firms could calculate proportion of association with Microsoft's brand, partner's brand and association with none of the two

3. Evaluate contribution of respective brands to revenue

- firms could draw bar chart showing demand drivers ranked according to their contribution to purchasing decisions of an individual customer (and consequently revenue niche player generates off that customer)

- by splitting each bar according to proportion of association with each respective brand, firms could easily read off chart what percentage of their revenues is actually generated due to association of their offerings with Microsoft's brand

Figure 3 presents example of such chart. It is based on demand drivers in high-tech B2B industry, suggested by Munoz and Kumar (2004).

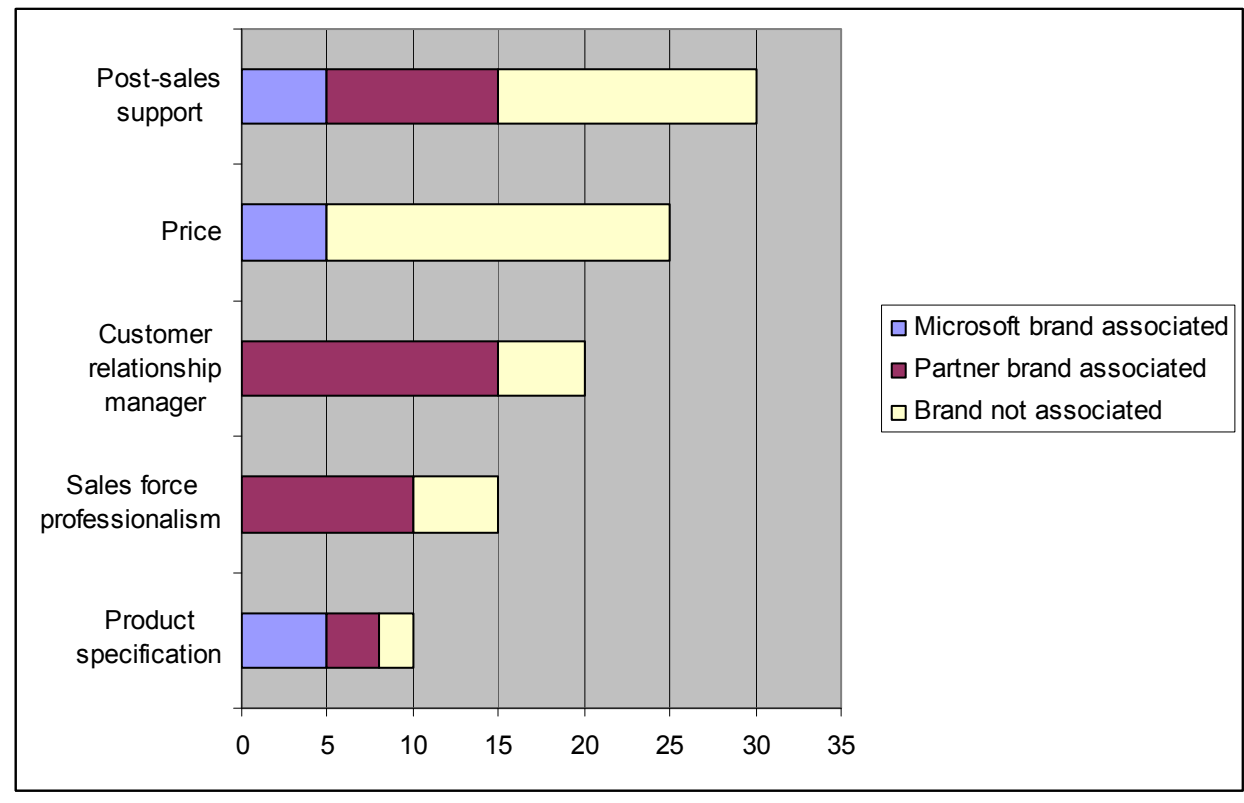

Figure 3. Contribution of respective brands to total revenues in hypothetical example

In this hypothetical example, $15 \%$ of niche player's total revenue off a particular customer is driven by customer's association of niche player's offerings with Microsoft's brand. By calculating such proportions for all customers, niche player could estimate value of association of its offerings with Microsoft's brand, or in terminology of dynamic capabilities literature, to what extent does dynamic capability of integration of external marketing competencies 
contribute to top-line performance.

\section{Conclusions}

In this paper rudimentary effort to estimate performance impact of dynamic capabilities is presented. Empirical investigation of dynamic capabilities in networked environment revealed that the most important benefit to small firms when partnering with large firms is enhanced credibility of small firm (niche player) as a supplier and as a business partner. As credibility rests on perception of a firm, affected by brand image and impact, this paper endeavours to develop system which would help niche players gauge proportion of their revenues that is driven by brand impact of their large partner. Paper presents relationship capability as a concept of strategy that involves dynamic capability of integrating external competencies. It shows that in the context of technology industries, niche players integrate both marketing and technological competencies to particular extent when they partner with standard-setting large firms. Integration of marketing competencies of large firms occurs primarily through co-branding, suggesting that there is some kind of linkage between dynamic capabilities and brand impact. Paper integrates brand measurement approaches with concept of dynamic capabilities to arrive at rough measure of performance contribution of dynamic capabilities. In future work, refinement of brand impact measurement, as well as more thorough treatment of competencies that are integrated will contribute to development of more robust and generally acceptable dynamic capabilities measurement metrics.

\section{References}

Argyris, C., \& Schon, S. (1978). Organizational Learning: A Theory of Action Perspective. Addison-Wesley.

Clark, K., \& Fujimoto, T. (1991). Product development performance: strategy, organization and performance in the world auto industries. Cambridge, MA, Harvard Business School Press.

Della Corte, V., \& Del Gaudio, G. (2012). Dynamic capabilities: a still unexplored issue with growing complexity. Corporate Ownership \& Control, 9(4), 327-339.

Dyer, J., \& Singh, H. (1998). The relational view: cooperative strategy and sources of interorganizational competitive advantage. Academy of Management Review, 23(4), 660-679. http://dx.doi.org/10.5465/AMR.1998.1255632

Eisenhardt, K. M. (1989). Building theories from case study research. Academy of Management Review, 14(4), 543-576. http://dx.doi.org/10.5465/AMR.1989.4308385

Eisenhardt, K. M., \& Martin, J. (2000). Dynamic capabilities: What are they? Strategic Management Journal, $21(10 / 11)$, http://dx.doi.org/10.1002/1097-0266(200010/11)21:10/11<1105::AID-SMJ133>3.0.CO;2-E

1105-1121.

Glaser, B., \& Strauss, A. (1967). The discovery of grounded theory: Strategies of qualitative research. London: Wiedenfeld and Nicholson.

Gulati, R. (1999). Network location and learning: the influence of network resources and firm capabilities on alliance formation. Strategic Management Journal, http://dx.doi.org/0.1002/(SICI)1097-0266(199905)20:5<397::AID-SMJ35>3.0.CO;2-K.

Helfat, C. E., \& Raubitschek, R. S. (2000). Product sequencing: co-evolution of knowledge, capabilities and products. Strategic Management Journal, 21(10-11), 961-979. http://dx.doi.org/10.1002/1097-0266(200010/11)21:10/11<961::AID-SMJ132>3.0.CO;2-E

Iansiti, M., \& Levien, R. (2004a). Strategy as Ecology. Harvard Business Review, 82(3), 68.

Iansiti, M., \& Levien, R. (2004b). The Keystone Advantage: What the New Dynamics of Business Ecosystems Mean for Strategy, Innovation and Sustainability. Boston, MA: Harvard Business School Press.

Munoz, T., \& Kumar, S. (2004). Brand metrics: Gauging and linking brands with business performance. Brand Management, 11(5), 381-387.

Nelson, R. R., \& Winter, S. (1982). An Evolutionary Theory of Economic Change. The Belknap Press: Cambridge, MA.

Pavlou, P. A., \& El Sawy, O. A. (2011). Understanding the elusive black box of dynamic capabilities. Decision Sciences, 42(1), 239-273. http://dx.doi.org/10.1111/j.1540-5915.2010.00287.x

Powell, W. W., Koput, K. W., \& Smith-Doerr, L. (1996). Interorganizational collaboration and the locus of innovation: networks of learning in biotechnology. Administrative Science Quarterly, 41(1), 116-135. http://dx.doi.org/10.2307/2393988 
Schumpeter, J. A. (1942). Capitalism, Socialism, and Democracy. New York: Harper.

Teece, D., Pisano, G., \& Shuen, A. (1997). Dynamic capabilities and strategic management. Strategic Management Journal, $18(7)$ 509-533. http://dx.doi.org/10.1002/(SICI)1097-0266(199708)18:7<509::AID-SMJ882>3.0.CO;2-Z

Wang, C. L., \& Ahmed, P. K. (2007). Dynamic capabilities: A review and research agenda. International Journal of Management Reviews, 9(1), 31-51. http://dx.doi.org/10.1177/0149206309350776

Wernerfelt, B. (1984). A resource-based view of the firm. Strategic Management Journal, 5(2), 171-180. http://dx.doi.org/10.1002/smj.4250050207

Winter, S. G. (2003). Understanding dynamic capabilities. Strategic Management Journal, 24(10), 991-995. http://dx.doi.org/10.1002/smj.318

Zollo, M., \& Winter, S. G. (2002). Deliberate learning and the evolution of dynamic capabilities. Organization Science, 13(3), 339-351. http://dx.doi.org/10.1287/orsc.13.3.339.2780 